\title{
A single robust stability-indicating RP-HPLC analytical tool for apigenin quantification in bulk powder and in nanoliposomes: a novel approach
}

\author{
Priya Shetti ${ }^{1}$ and Sunil S. Jalalpure $2^{2^{*}}$
}

\begin{abstract}
Background: Apigenin (4', 5, 7-trihydroxyflavone), a flavonoid, is present usually in fruits and vegetables possessing numerous biological properties like antioxidant, anti-viral, antibacterial, anti-inflammatory, and chemoprevention activity. So present study was aimed to prepare and characterize nanoliposomes of apigenin and estimate its encapsulation efficiency by stability-assisted reverse-phase (RP)-HPLC method.

Results: The stability indication of the RP-HPLC method developed for apigenin-loaded nanoliposomes was successfully demonstrated and parameters were mainly the retention time which was 4.21 min, limit of detection (LOD) $0.49 \mu \mathrm{g} / \mathrm{mL}$, limit of quantification (LOQ) $1.48 \mu \mathrm{g} / \mathrm{mL}$, and \%relative standard deviation (RSD) less than $2 \%$. Therefore, the stability indication of the developed reverse-phase HPLC method for apigenin-loaded nanoliposomes was demonstrated successfully and parameters like accuracy, linearity, LOD, LOQ, precision, and \%RSD were within the limit range and found to be satisfactory.

Conclusion: The developed RP-HPLC method was found to be suitable for the quantification or estimation of apigenin with its stability in apigenin-loaded nanoliposomes, and this method will be a powerful tool in the future for the estimation of apigenin present in any pharmaceutical preparations.
\end{abstract}

Keywords: Apigenin, Nanoliposomes, Stability-indicating method, RP-HPLC, Validation

\section{Background}

Apigenin (4,5,7-trihydroxyflavone) (Fig. 1) is one of the most novel flavonoids in plants and formally belongs to the flavone sub-class. Apigenin possess moderate antioxidant property, anti-hyperglycemic [1], anti-inflammatory [2], myocardial ischemia, and anti-apoptotic effects [3]. A review by Zhou et al. summarized various biological effects of apigenin being effective against cytostatic and cytotoxic activities of a number of cancer cells and antiatherogenic effects and also protective effects on hypertension, cardiac hypertrophy, and autoimmune

\footnotetext{
* Correspondence: jalalpuresunil@rediffmail.com

${ }^{2}$ KLE College of Pharmacy, Belagavi, KLE Academy of Higher Education and Research, Nehru, Belagavi, Karnataka 590010, India

Full list of author information is available at the end of the article
}

myocarditis [4]. Novel approach has led to the development of apigenin in the pharmaceutical era, and quantification and estimation of apigenin in plant extracts has need raised. Nanoliposomes are similar to nano-metric kind of liposomes which tend to be the further most applied in encapsulation and controlled release systems [5]. These deliver more surface area, compared to liposomes, hence enhancing the bioavailability and controlled release, facilitating accurate target of the encapsulated material to a larger amount [6]. Apigenin having potential to increase the performance of the bioactive agent helps in enhancing solubility, bioavailability, and stability reported in vitro and in vivo. Due to prevention in unnecessary interactions with other molecules with this support, these nanoliposomes have diverse applications; current study was 


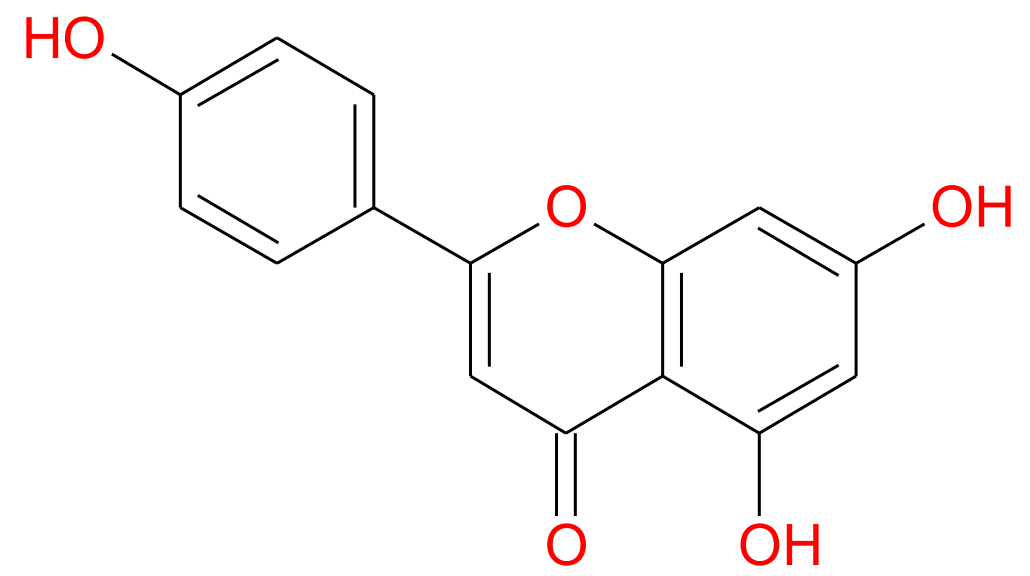

Fig. 1 Chemical structure of apigenin

commenced for the preparation, characterization, and confirmation of apigenin-loaded nanoliposomes for its encapsulation stability by RP-HPLC method.

\section{Methods}

\section{Chemicals and reagents}

Apigenin was a gift sample from Aktin Chemicals Ltd., China. Methanol, acetonitrile, and formic acid (HPLC grade) were purchased from Merck Limited (Mumbai, India). Other common laboratory reagents were of analytical grade.

\section{Instrumentation}

Shimadzu HPLC (LC- 2010) (Kyoto, Japan), pump system (LC-20 AD), degasser (DGU-20A5), a column oven (CTO-10ASVP), an auto-injector (SIL-20ACHT), PDA Detector (SPD-M20A), and a computer software (lab solutions, version 1.25 ) were used.

\section{Chromatographic conditions}

The chromatographic separation was carried out by injecting $(10 \mu \mathrm{L})$ a sample to the HPLC system connected to a C-18 analytical column (Phenomenex Luna $5 \mu \mathrm{m}, 250 \mathrm{~mm} \times 4.6 \mathrm{~mm}$ ) (set at $35^{\circ} \mathrm{C}$ ) operating at 1 $\mathrm{ml} / \mathrm{min}$ flow rate, and detection was done at $269 \mathrm{~nm}$. Acetonitrile and $0.1 \%$ formic acid, $55: 45(\mathrm{v} / \mathrm{v})$ at $\mathrm{pH}=$ 7.4, was used as a mobile phase.

Table 1 Results of system suitability studies of quality control samples of apigenin

\begin{tabular}{lll}
\hline Parameter & Mean \pm SD & \% RSD \\
\hline Retention time $(\mathrm{min})$ & $4.21 \pm 0.00^{\mathbf{a}}$ & 0.13 \\
Peak area & $127512 \pm 273^{\mathbf{a}}$ & 0.21 \\
Theoretical plates & $7010 \pm 38.23^{\mathbf{a}}$ & 0.54 \\
Tailing factor & $1.35 \pm 0.00^{\mathbf{a}}$ & 0.22 \\
\hline $\begin{array}{l}\text { RSD relative standard deviation } \\
{ }^{\mathrm{a}} \boldsymbol{n}=6\end{array}$ & &
\end{tabular}

\section{Standard solution preparation}

Stock solution was prepared $(100 \mu \mathrm{g} / \mathrm{mL})$ in the mobile phase. Further dilutions were carried out to get the calibration curve ranging from 0.5 to $16 \mu \mathrm{g} / \mathrm{mL}$.

\section{Preparation of stealth apigenin-nanoliposomes}

Formulating the stealth apigenin-nanoliposomes, an ethanol injection technique was used in the preparation of nanoliposomes as described by Sudhakar et al. [7]. Briefly, apigenin $(10 \mathrm{mg})$ and stearic acid $(10 \mathrm{mg})$ were dissolved in $2 \mathrm{ml}$ of absolute ethanol with gentle heating $\left(<50{ }^{\circ} \mathrm{C}\right)$ on a hot plate. Then, lipid di-stearoyl-sn-glycero-phosphoethanolamine-N (polyethyleneglycol) (DSPE-PEG) (0.003\%) and cholesterol $(0.0015 \%)$ were added into the same mixture with stirring. Phosphatebuffered saline (PBS) (pH 7.4) (10 ml) was added to mixture dropwise with constant stirring for 90-120 $\mathrm{min}$ to remove ethanol. The nanoliposomes were optimized for various concentrations of lipid. The optimized batch was homogenized at $10,000 \times g$ for $10 \mathrm{~min}$ followed by sonication for $15 \mathrm{~min}$, which were further filtered through $0.45-\mu \mathrm{m}$ and $0.2-\mu \mathrm{m}$ sterile syringe filters and were allowed to equilibrate for 1 day and then stored at $4{ }^{\circ} \mathrm{C}$. In the time, apigenin-loaded nanoliposomes were also assessed for their average particle size, poly dispersity index (PDI) according to Sharma et al. [8]. Moreover, encapsulation efficiency of nanoliposome was also assessed by centrifugation at $10,000 \times g$ for $30 \mathrm{~min}$, and supernatant solution obtained after centrifugation was mixed with mobile phase and analyzed by using HPLC $[9,10]$.

\section{Method development}

The chromatographic conditions were optimized and steady baseline was obtained. Chromatogram was assessed by injecting standard apigenin solution, and analyses were repeated in a similar way for six times. 


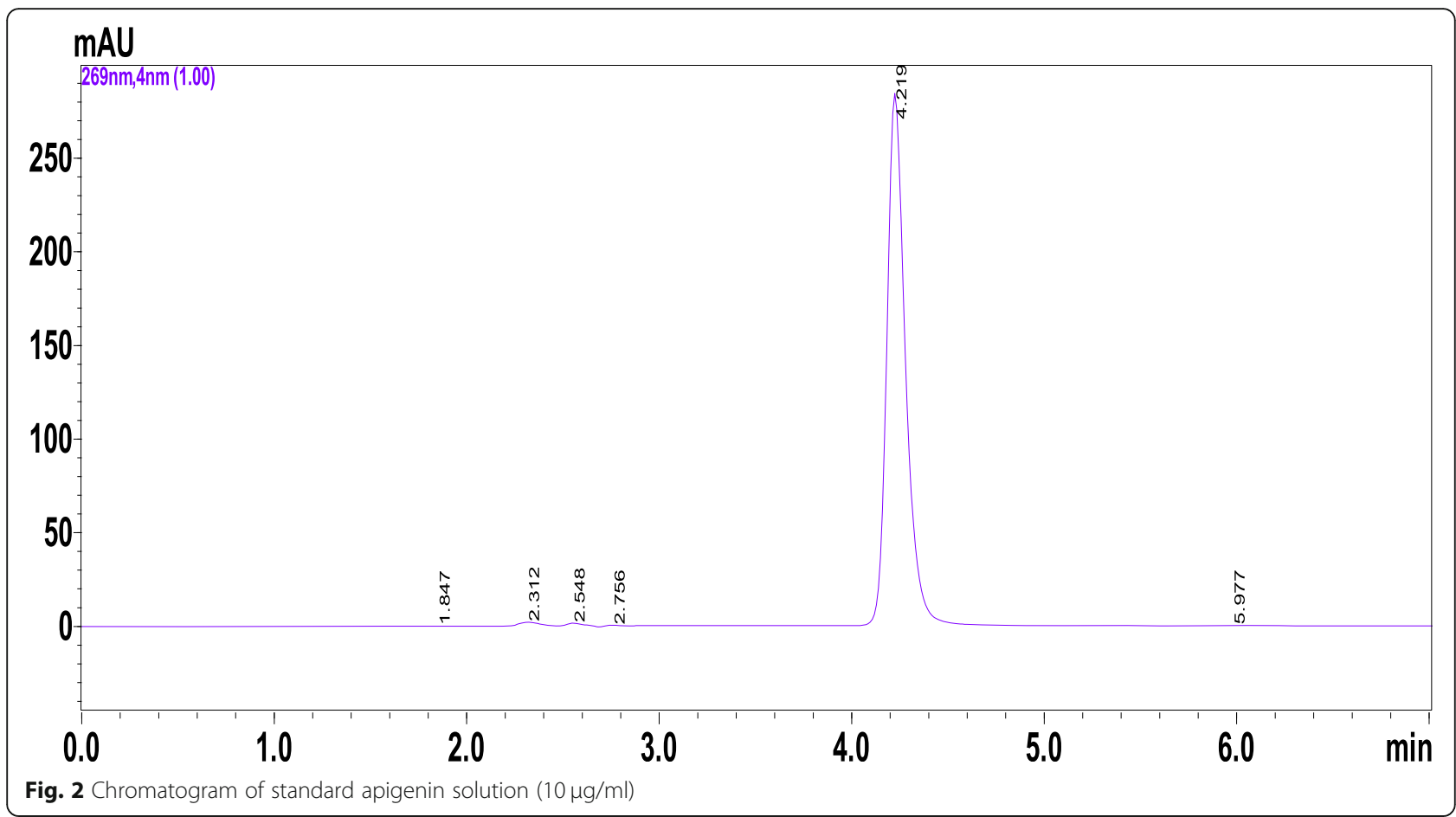

\section{Method validation \\ Linearity}

Linearity studies reveal the standard calibration curve was plotted from 0.5 to $16 \mu \mathrm{g} / \mathrm{mL}$ concentrations. Standard calibration curves were determined for concentrations versus peak area. Sample run in triplicate of all the sample solutions was assessed, and a chromatogram was recorded.

\section{Precision and accuracy}

The apigenin samples were subjected to three levels of quality control; namely low, medium, and high respective concentrations of $0.5,4$, and $16 \mu \mathrm{g} / \mathrm{mL}$ were prepared and used in determining the precision and accuracy. For intra-day precision and accuracy, triplicates of standard solutions were injected on the same day and also for interday; triplicates of standard solutions (50\%, 100\%, and $150 \%$ ) were injected over three consecutive days.

Table 2 Results of linearity and regression analysis of apigenin

\begin{tabular}{ll}
\hline Analyte & Apigenin at $\mathbf{2 6 9} \mathbf{~ n m}$ \\
\hline Concentration range $(\mu \mathrm{g} / \mathrm{ml})$ & $0.5-16$ \\
Slope & 34,367 \\
Intercept & 5495 \\
$\mathrm{R}^{2}$ & 0.999 \\
$\mathrm{LOD}(\mu \mathrm{g} / \mathrm{ml})$ & 0.49 \\
$\mathrm{LOQ}(\mu \mathrm{g} / \mathrm{ml})$ & 1.48 \\
\hline
\end{tabular}

\%relative standard deviation (RSD) and \% RE were calculated respectively.

Limit of detection (LOD) and limit of quantification (LOQ) The LOD was determined by a series of dilutions of apigenin stock solutions to find a signal to noise $(\mathrm{S} / \mathrm{N})$ ratio of at least 3.3:1 for LOD and 10:1 for LOQ. Both parameters obliged the quantity of analyte that can be quantified.

\section{System suitability}

To validate the chromatographic system, suitability test is carried out, and various factors such as tailing factor, theoretical plates, and peak area and resolution data were also considered.

\section{Robustness}

The robustness of the method was evaluated by deliberately making a slight change in the optimized value. The evaluated parameters were as follows: detector wavelength $( \pm 1 \mathrm{~nm})$, flow rate $( \pm 0.2 \mathrm{ml} / \mathrm{min})$, and oven temperature $\left( \pm 2{ }^{\circ} \mathrm{C}\right)$. Apigenin peak areas and the $\%$ RSD of robustness testing were statistically measured.

\section{Specificity}

The specificity study chance of interferences from PBS and apigenin-loaded nanoliposomes at the retention time of apigenin was analyzed by comparing the chromatograms obtained from the standard apigenin solution and PBS. 


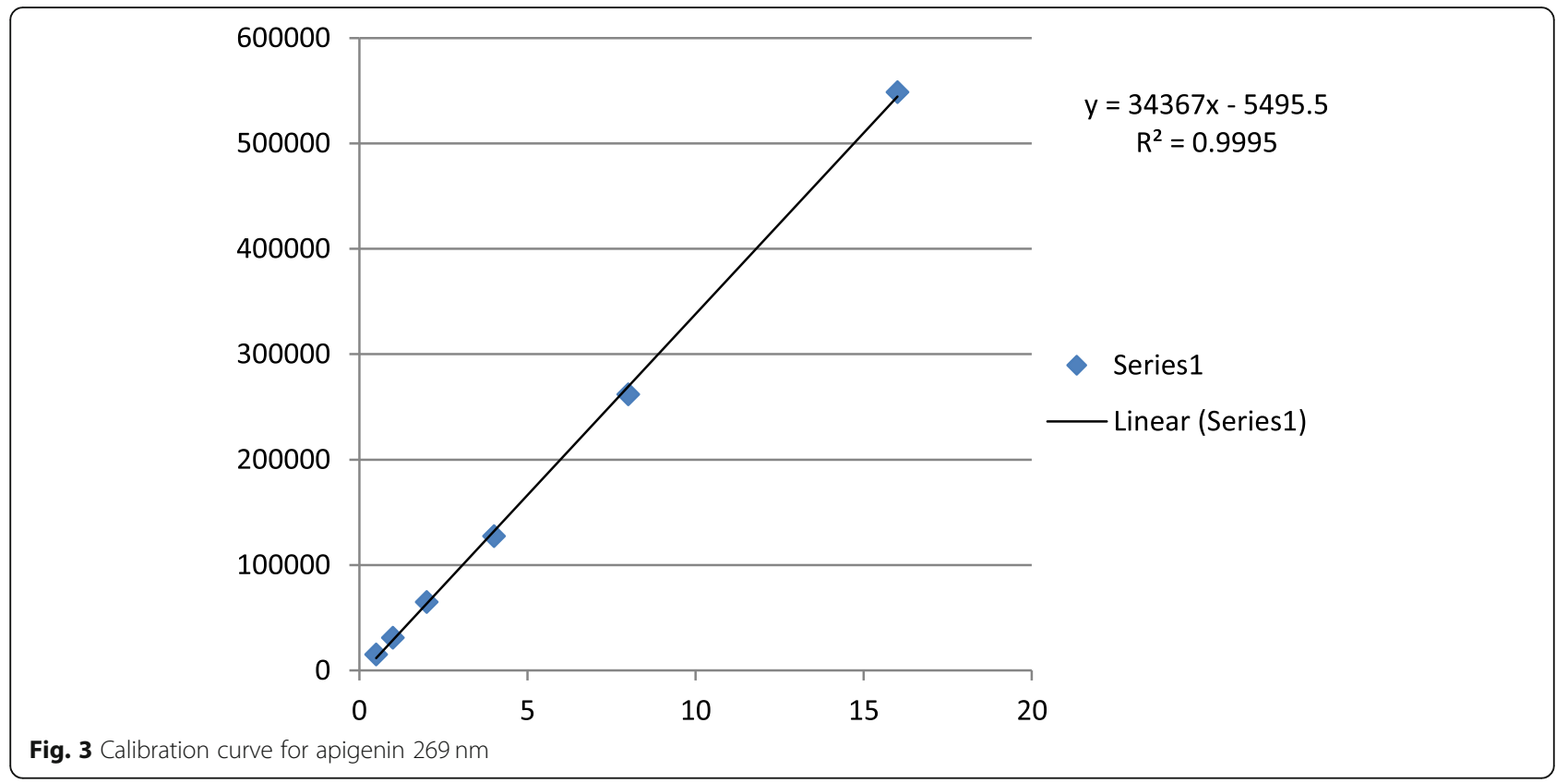

\section{Force degradation studies}

The stability-indicating property of the HPLC method which was developed was carried out as per the International Conference on Harmonization (ICH) guidelines [11]. Forced degradation studies of apigenin were conducted by exposing the working sample to oxidation, photolytic, acidic, and alkaline and heat conditions.

\section{Results}

Optimization of sample preparation and chromatographic conditions

Various trials were performed by changing the composition of the mobile phase. Finally, composition of ACN, $0.1 \%$ FA $(55: 45 \mathrm{v} / \mathrm{v}, \mathrm{pH}=7.4)$, gave the better separation. During these studies, the $10 \mu \mathrm{l}$ injected volume and the flow rate $(1 \mathrm{ml} / \mathrm{min})$ found to be constant.

\section{Analytical method validation suitability of system}

The system suitability results are tabulated in Table 1 . The peak retention time was found to be $4.21 \mathrm{~min}$ (Fig. 2), the average theoretical plate was $>7000$, and the tailing factor was $<2$. Presence of higher theoretical plates with a lower tailing number indicates the efficiency of the system. Additionally, the \% RSD values for all the parameters

Table 3 Results of accuracy study of apigenin

\begin{tabular}{lllllll}
\hline $\begin{array}{l}\text { Sl. } \\
\text { No. }\end{array}$ & $\begin{array}{l}\text { Conc. } \\
(\boldsymbol{\mu} \mathbf{g} / \mathbf{m l})\end{array}$ & $\begin{array}{l}\text { Level } \\
\text { in }(\%)\end{array}$ & $\begin{array}{l}\text { Added qty } \\
(\boldsymbol{\mu} \mathbf{g} / \mathbf{m l})\end{array}$ & $\begin{array}{l}\text { Found qty } \\
(\boldsymbol{\mu} \mathbf{g} / \mathbf{m l})\end{array}$ & $\begin{array}{l}\text { Recovery } \\
(\%)\end{array}$ & $\begin{array}{l}\text { RSD } \\
(\%)\end{array}$ \\
\hline $\mathbf{1}$ & 2 & 50 & 1 & 1.02 & 99.96 & 0.76 \\
$\mathbf{2}$ & 2 & 100 & 2 & 2.00 & 100.20 & 0.28 \\
$\mathbf{3}$ & 2 & 150 & 3 & 3.15 & 101.40 & 0.12 \\
\hline
\end{tabular}

$R S D$ relative standard deviation including retention time, peak area, and theoretical plates and tailing number were less than $1 \%$ justifying the better suitability of the system.

\section{Linearity and range}

The linearity and regression are tabulated in Table 2 and Fig. 3. None of the constituents from the nanoliposomes or the derivative products of stress treatment interfered with apigenin peaks. A calibration curve was generated by plotting concentration of apigenin $(\mathrm{x})$ against the peak area. A linearity $\left(R^{2}=0.9995\right.$; equation $\mathrm{y}=$ $34367 \mathrm{x}-5495.5)$ was achieved for the concentration range of $0.5-16 \mu \mathrm{g} / \mathrm{mL}$. Apigenin was detected employing $\mathrm{C}_{18}$ column with methanol to $0.2 \%$ phosphoric acid mobile phase and had an accuracy and recovery of 93.82 and $88.35 \%$ respectively.

Limit of detection (LOD) and limit of quantification (LOQ) The LOD and LOQ of apigenin were found to be 0.49 and $1.48 \mu \mathrm{g} / \mathrm{ml}$, respectively. A higher LOD $(1.94 \mu \mathrm{g} / \mathrm{ml})$ and LOQ $(6.26 \mu \mathrm{g} / \mathrm{ml})$ of apigenin was reported.

\section{Accuracy and precision}

The obtained results are expressed in Tables 3, 4, and 5 . The intra-day precision for apigenin was between 0.11 and $1.38 \%$, while the accuracy ranged between 0.12 and $0.76 \%$. The interday precision was $0.27 \%$ and $1.69 \%$, respectively. Three separate samples injected showed a best recovery of $99.96-101.4 \%$ indicating a higher accuracy of the method. 
Table 4 Results of intra-day precision of apigenin solution

\begin{tabular}{lllll}
\hline $\begin{array}{l}\text { Experiment time } \\
\text { for day } \mathbf{1}\end{array}$ & $\begin{array}{l}\text { Concentration } \\
(\boldsymbol{\mu} \mathbf{g} / \mathbf{m l})\end{array}$ & $\begin{array}{l}\text { Peak } \\
\text { area }\end{array}$ & $\begin{array}{l}\text { Retention } \\
\text { time }(\mathbf{m i n})\end{array}$ & $\begin{array}{l}\text { (\%)RSD of } \\
\text { peak area }\end{array}$ \\
\hline 9:00 am & 0.5 & $19,404.17$ & 4.28 & 1.38 \\
& 4 & 129,483 & 4.29 & 0.39 \\
& 16 & $673,361.8$ & 4.30 & 0.78 \\
1:00 pm & 0.5 & $19,404.17$ & 4.31 & 1.38 \\
& 4 & $129,707.2$ & 4.29 & 0.27 \\
& 16 & $673,361.8$ & 4.28 & 1.05 \\
$6: 00 \mathrm{pm}$ & 0.5 & $19,497.17$ & 4.27 & 0.34 \\
& 4 & $129,882.5$ & 4.27 & 0.32 \\
& 16 & 682,828 & 4.28 & 0.11 \\
\hline
\end{tabular}

$R S D$ relative standard deviation

\section{Robustness and ruggedness}

The results of the robustness study are presented in Table 6. Parameters including mobile phase, flow rate, detection wavelength, column oven temperature, and the type of column did not hinder the resolution in terms of similar retention time and lower RSD values.

\section{Stability-indicating study}

The results of the stress degradation studies (acid, alkali, oxidation, heat, and light) for the standard apigenin solution are shown in Table 7. The chromatograms of the stressed standard apigenin solution after $2 \mathrm{~h}$ under various stress conditions are shown in Figs. 4 and 5. In the current study, apigenin showed a degree of degradation ranging from as low as $5.87 \%$ for alkaline hydrolysis to $20 \%$ by photolytic damage. The degradation of apigenin was perfectly estimated by the developed method. HPLC analysis of aqueous and ethanolic chamomile extracts exposed to different temperature and $\mathrm{pH}$ showed that apigenin-7-O-glucosidedegraded by $6 \%$ at $\mathrm{pH} 8,9 \%$ at $\mathrm{pH} 9$, and $11-12 \%$ at $\mathrm{pH} 10-12 ; 48 \%$ at $\mathrm{pH} 13.0$, with no loss below pH 5.0. Long-term storage of extracts at room temperature revealed conversion of glycoside to aglycone as compared to storage at $-20^{\circ} \mathrm{C}$.

Table 5 Results of interday precision data of apigenin samples

\begin{tabular}{lllll}
\hline $\begin{array}{l}\text { Day / } \\
\text { time }\end{array}$ & $\begin{array}{l}\text { Concentration } \\
(\boldsymbol{\mu} \mathbf{g} / \mathbf{m l})\end{array}$ & $\begin{array}{l}\text { Peak } \\
\text { area }\end{array}$ & $\begin{array}{l}\text { Retention } \\
\text { time }(\mathbf{m i n})\end{array}$ & $\begin{array}{l}\text { (\%)RSD of } \\
\text { peak area }\end{array}$ \\
\hline Day 1 10: & 0.5 & $18,728.5$ & 4.28 & 0.93 \\
00 am & 4 & $129,084.2$ & 4.29 & 0.28 \\
& 16 & $647,448.3$ & 4.30 & 1.16 \\
Day 2 10: & 0.5 & $19,404.17$ & 4.31 & 1.38 \\
00 am & 4 & $129,707.2$ & 4.29 & 0.27 \\
& 16 & $673,361.8$ & 4.28 & 1.05 \\
Day 3 10: & 0.5 & 20,680 & 4.30 & 1.69 \\
00 am & 4 & 130,179 & 4.29 & 0.27 \\
& 16 & $721,931.5$ & 4.28 & 1.02 \\
\hline
\end{tabular}

$R S D$ relative standard deviation
Table 6 Analysis of robustness and ruggedness using apigenin solution

\begin{tabular}{llll}
\hline Parameters & Variations & Time (min) & \%RSD \\
\hline Mobile phase $( \pm 2 \mathrm{v} / \mathrm{v})$ & $55: 45$ & 4.30 & 0.08 \\
& $53: 47$ & 4.51 & 0.10 \\
& $57: 43$ & 4.00 & 0.03 \\
Flow rate $\pm 0.1 \mathrm{ml})$ & $1 \mathrm{ml} / \mathrm{min}$ & 4.33 & 0.08 \\
& $0.9 \mathrm{ml} / \mathrm{min}$ & 4.71 & 0.10 \\
& $1.1 \mathrm{ml} / \mathrm{min}$ & 3.86 & 0.09 \\
Detection wavelength $( \pm 2 \mathrm{~nm})$ & 267 & 4.24 & 0.13 \\
& 269 & 4.23 & 0.11 \\
Column oven temp $\left( \pm 1{ }^{\circ} \mathrm{C}\right)$ & $35{ }^{\circ} \mathrm{C}$ & 4.21 & 0.13 \\
& $34{ }^{\circ} \mathrm{C}$ & 4.22 & 0.15 \\
& $36{ }^{\circ} \mathrm{C}$ & 4.20 & 0.17 \\
Column & Luna 5u(250X4.6) & 4.33 & 0.08 \\
& Luna 5u(150X4.6) & 3.84 & 0.09 \\
\hline
\end{tabular}

$R S D$ relative standard deviation

Preparation and characterization of stealth liposomes The apigenin-loaded nanoliposomes were successfully prepared by the ethanol injection technique; the nanoliposomes was $124 \mathrm{~nm}$ of the blank liposome and apigenin-loaded liposome was $151 \mathrm{~nm}$. The average polydispersity index for blank and drug-loaded liposome was 0.23 and 0.16 , respectively (Table 8 ). These results summarized that the PDI value is $<0.3$ and indicated narrow homogeneous presence of particle size distribution. Meanwhile, these apigenin-loaded liposomes were also subjected to the encapsulation efficiency (EE) of apigenin in the formulation. The chromatogram showed an intense characteristic apigenin peak in nanoliposomes, and $\mathrm{t} 80.18 \%$ of encapsulation efficiency was achieved by this method (Fig. 6, Table 8).

The average particle size of apigenin-loaded lecithin liposomes was in the range of $158.9 \pm 6.1$ to $260.3 \pm 11.1$ $\mathrm{nm}$. The PDI ranged from $0.205 \pm 0.02$ to $0.331 \pm 0.063$ with a remarkable encapsulation efficiency of more than 92\% and possessing high potential for nutraceutical formulations. In another study, apigenin-loaded distearoylphophatidylcholine (DSPC) liposomes showed a particle

Table 7 Results of the stress degradation studies of apigenin solution at $2 \mathrm{~h}$

\begin{tabular}{llll}
\hline $\begin{array}{l}\text { Stress } \\
\text { degradation } \\
\text { studies }\end{array}$ & $\begin{array}{l}\text { Conc. used } \\
(\boldsymbol{\mu g} / \mathbf{m l})\end{array}$ & $\begin{array}{l}\text { Conc. left after } \\
\text { degradation }(\boldsymbol{\mu g} / \mathbf{m l})\end{array}$ & $\begin{array}{l}\% \\
\text { Degradation }\end{array}$ \\
\hline Acid hydrolysis & 2.0 & 1.62 & 18.88 \\
$\begin{array}{l}\text { Alkaline } \\
\text { hydrolysis }\end{array}$ & 2.0 & 1.88 & 5.87 \\
Oxidation & 2.0 & 1.70 & 14.61 \\
Thermal & 2.0 & 1.66 & 16.55 \\
Photolytic & 2.0 & 1.60 & 20.00 \\
\hline
\end{tabular}




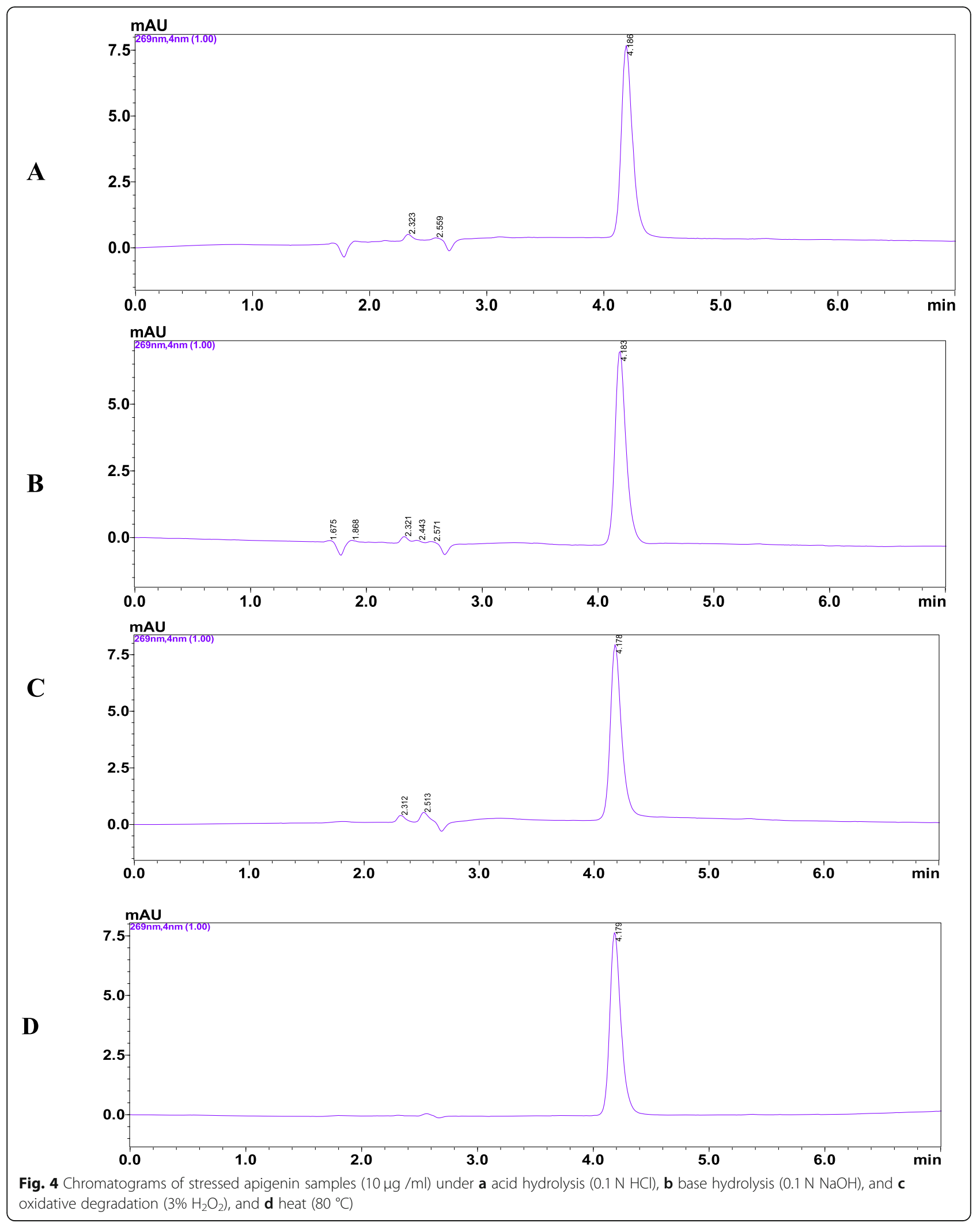




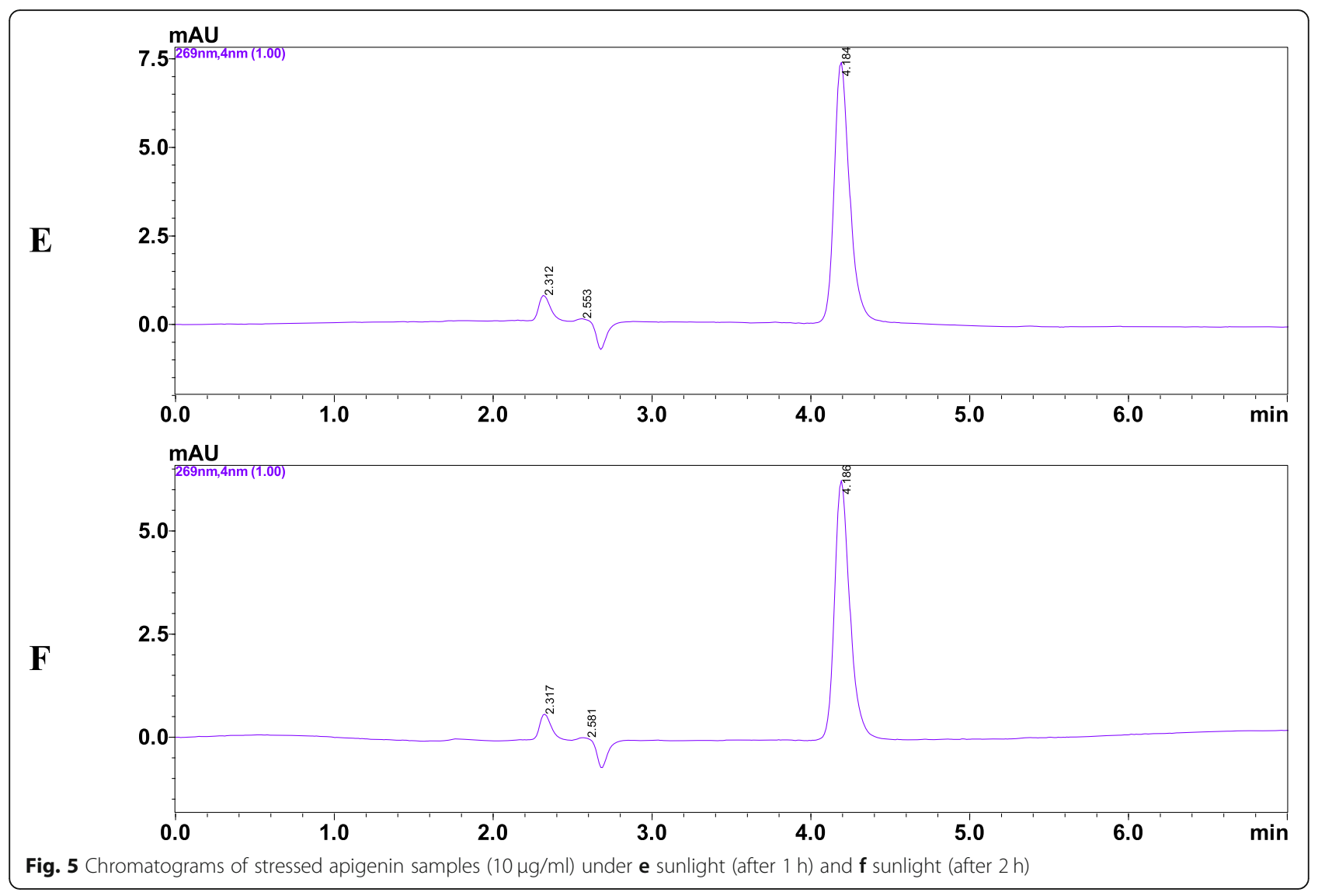

size of $104.3 \pm 1.8 \mathrm{~nm}$, PDI of 0.204 , and a high EE of 89.9\%. The apigenin-loaded DSPC liposomes were effective in delivering the drug within bacterial cells and thus were antibacterial in nature.

\section{Discussion}

Presence of higher theoretical plates with a lower tailing number indicates the efficiency of the system. Additionally, the \% RSD values for all the parameters including retention time, peak area, and theoretical plates and tailing number were less than $1 \%$ justifying the better suitability of the system [12].

None of the constituents from the nanoliposomes or the derivative products of stress treatment interfered with apigenin peaks. A calibration curve was generated by plotting concentration of apigenin $(x)$ against the peak area. A linearity of $r=0.9995$ with equation $y=34367 x-5495.5$ was achieved for the concentration range of $0.5-16 \mu \mathrm{g} / \mathrm{ml}$. Apigenin was detected utilizing $\mathrm{C}_{18}$ column with methanol to $0.2 \%$ phosphoric acid mobile [13]. A higher LOD $(1.94 \mu \mathrm{g} /$ $\mathrm{ml})$ and LOQ $(6.26 \mu \mathrm{g} / \mathrm{ml})$ of apigenin was reported, which could be due to variance in the mobile phase [13] and depending on the type of analysis and analytical conditions used [12]. Three separate samples injected showed a best recovery of $99.96-101.4 \%$ indicating a higher accuracy of the method. The RSD values of intra- and interday precision of the method was less than $2 \%$ [14-16].

Parameters including mobile phase, flow rate, detection wavelength, column oven temperature, and the type of column did not hinder the resolution in terms of similar retention time and lower RSD values. Triplicate analysis of the samples showed the better robustness of the developed method which was similar to those reported [17].

In the current study, apigenin showed a degree of degradation ranging from as low as $5.87 \%$ for alkaline

Table 8 Results of characterization of apigenin-entrapped liposomes

\begin{tabular}{llll}
\hline Liposome formulation & Particle size diameter $(\mathbf{n m})$ & PDI & \% Entrapment efficiency \\
\hline Blank liposome & 124 & 0.23 & NA \\
Apigenin-loaded liposomes & 151 & 0.16 & $80.18 \%$
\end{tabular}




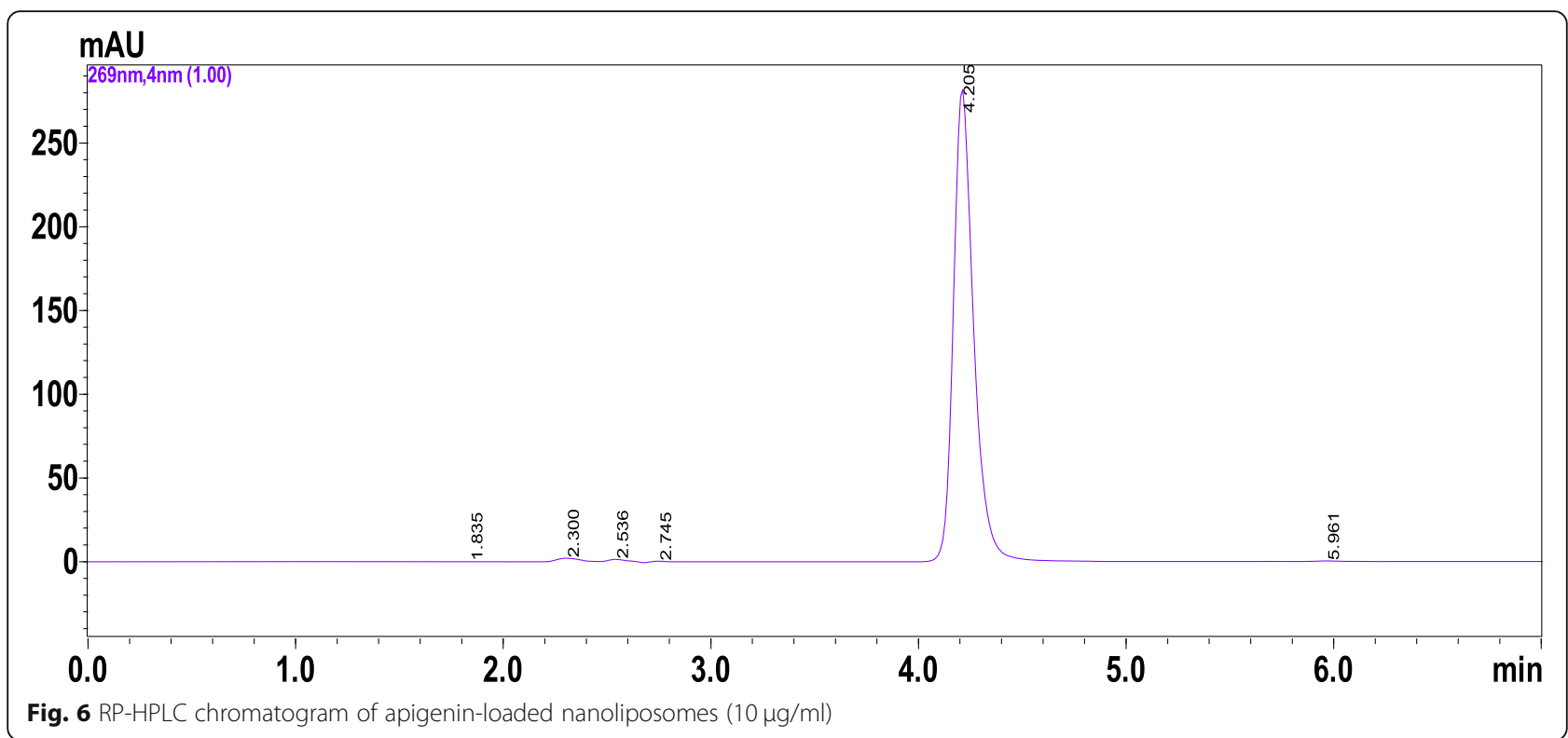

hydrolysis to $20 \%$ by photolytic damage. The degradation of apigenin was perfectly estimated by the developed method [18]. Apigenin was also found to be structurally unstable when subjected to temperatures of $37^{\circ} \mathrm{C}[19,20]$.

A multiple emulsion solvent evaporation technique was employed to encapsulate apigenin in poly(lactideco-glycoside), PLGA, which showed a drug loading efficacy of $19.14 \%$ [21]. The EE of apigenin-loaded liposomes was better than that reported and similar to encapsulation of apigenin in lecithin liposomes [22]. The average particle size of apigenin-loaded lecithin liposomes was in the range of 158.9 to $260.3 \mathrm{~nm}$. The PDI ranged from 0.205 to 0.331 with a remarkable encapsulation efficiency of more than 92\%. In another study, apigenin-loaded distearoylphophatidylcholine (DSPC) liposomes showed a particle size of $104.3 \pm 1.8 \mathrm{~nm}$, PDI of 0.204 , and a high EE of $89.9 \%$. Apigenin-loaded nanoliposome from the current study would thus function as an efficient drug delivery system [23-25].

\section{Conclusion}

A sensitive, simple, specific, and stability-indicating RPHPLC tool for the quantification of apigenin bulk and apigenin-loaded nanoliposomes were developed effectively. Interferences of peaks with apigenin by the encapsulation substances were not detected. The method could be used in herbal drug industries for quantification of apigenin.

\section{Abbreviations}

RP-HPLC: Reverse-phase high-performance liquid chromatography; PDI: Polydispersity index; LOD: Limit of detection; LOQ: Limit of quantification: RSD: Relative standard deviation; PBS: Phosphate-buffered saline; EE: Encapsulation efficiency; DSPC: Distearoylphophatidylcholine;
ICH: International Conference on Harmonization; DSPE-PEG: Di-stearoyl-snglycero-phosphoethanolamine (polyethyleneglycol)

Acknowledgements

The authors are thankful to Aktin chemicals, China, for providing the drug as a gift sample. Authors are also thankful to KAHER's BSRC, Belagavi, for providing the facility.

\section{Authors' contributions}

PS contributed for experimental work and manuscript preparation. SSJ contributed in hypothesis and finalization of manuscript. All authors have read and approved the manuscript.

\section{Funding}

KLE Academy of Higher Education and Research (formerly known as KLE University), Belagavi, Karnataka, India, provided the financial support and necessary facilities for this research work.

Availability of data and materials

Authors declare to produce the data and material on demand/request.

\section{Declarations}

Ethics approval and consent to participant

Not applicable.

\section{Consent for publication}

Not applicable.

\section{Competing interests}

Authors do not have any conflict of interest.

\section{Author details}

${ }^{1}$ KAHER's Dr. Prabhakar Kore Basic Science Research Center, KLE Academy of Higher Education and Research, Nehru, Belagavi, Karnataka 590010, India.

${ }^{2}$ KLE College of Pharmacy, Belagavi, KLE Academy of Higher Education and Research, Nehru, Belagavi, Karnataka 590010, India.

Received: 22 February 2021 Accepted: 20 May 2021

Published online: 16 June 2021

\section{References}

1. Villa-Rodriguez JA, Kerimi A, Abranko L, Tumova S, Ford L, Blackburn RS, Rayner C, Williamson G (2018) Acute metabolic actions of the major 
polyphenols in chamomile: an in vitro mechanistic study on their potential to attenuate postprandial hyperglycaemia. Sci Rep 8(1):1-4

2. Lim R, Barker G, Wall CA, Lappas M (2013) Dietary phytophenolscurcumin, naringenin and apigenin reduce infection-induced inflammatory and contractile pathways in human placenta, foetal membranes and myometrium. Mol Hum Reprod 19(7):451-462

3. Zhou Z, Zhang Y, Lin L, Zhou J (2018) Apigenin suppresses the apoptosis of $\mathrm{H} 9 \mathrm{C} 2$ rat cardiomyocytes subjected to myocardial ischemia-reperfusion injury via upregulation of the PI3K/Akt pathway. Mol Med Rep 18(2):15601570

4. Zhou X, Wang F, Zhou R, Song X, Xie M (2017) Apigenin: a current review on its beneficial biological activities. J Food Biochem 41(4):12376

5. Mozafari MR, Mortazavi SM (2005) Nanoliposomes: from fundamentals to recent developments. Trafford Publishing Ltd, Oxford

6. Mozafari MR (2006) Nanocarrier technologies: frontiers of nanotherapy Springer, The Netherlands. https://doi.org/10.1007/978-1-4020-5041-1

7. Sudhakar B, Krishna MC, Murthy KV (2006) Factorial design studies of antiretroviral drug-loaded stealth liposomal injectable: PEGylation, lyophilization and pharmacokinetic studies. Appl Nanosci 6(1):43-60

8. Sharma A, Kaur M, Katnoria JK, Nagpal AK (2018) Polyphenols in food: cancer prevention and apoptosis induction. Curr Med Chem 25(36):47404757. https://doi.org/10.2174/0929867324666171006144208

9. Shukla S, Gupta S (2010) Apigenin: a promising molecule for cancer prevention. Pharm Res 27(6):962-978. https://doi.org/10.1007/s11095-0100089-7

10. Svehlikova V, Bennett RN, Mellon FA, Needs PW, Piacente S, Kroon PA, Bao Y (2004) Isolation, identification and stability of acylated derivatives of apigenin 7-O-glucoside from chamomile (Chamomillarecutita [L.] Rauschert). Phytochemistry. 65(16):2323-2332. https://doi.org/10.1016/.jphytochem.2004. 07.011

11. ICH 2005.International conference on harmonization of technical requirements for registration of pharmaceuticals for human use. Validation of analytical procedures: text and methodology. ICH Q2 (R1).

12. Rajagopal SS, Vazhayil BK, Varghese L, Nanjaian M (2017) Development and validation of RP-HPLC method for simultaneous determination of apigenin and luteolin in ethanol extract of Clerodendrum serratum (Linn.) Leaves. Asian J Appl Sci 5(1).

13. Li L, Jiang $\mathrm{H}, \mathrm{Wu} \mathrm{H}$, Zeng SU (2005) Simultaneous determination of luteolin and apigenin in dog plasma by RP-HPLC. J Pharm Biomed Anal 37(3):615620

14. Patel NG, Patel KG, Patel KV, Gandhi TR (2015) Validated HPTLC method for quantification of luteolin and apigenin in PremnamucronataRoxb., Verbenaceae. Adv Pharm Sci 2015:3

15. Li LP, Jiang HD (2006) Determination and assay validation of luteolin and apigenin in human urine after oral administration of tablet of Chrysanthemum morifolium extract by HPLC. J Pharm Biomed Anal 41(1): 261-265. https://doi.org/10.1016/j.jpba.2005.10.019

16. Koneru S, Rao DG, Rao BMV (2018) Validation of newly developed analytical method for standardization of apigenin using RP-HPLC method in prepared extract. Pharm Lett 10(3):30-36

17. Lazarević A, Petrovic S, Stanojevic J, Cvetkovic D, Stanojevic L, Zvezdanovic J (2018) Apigenin and apigetrin stability to UV-irradiation treatment in methanol solutions. In: Sixth International Conference on Radiation and applications in various fields of research

18. Srivastava JK, Gupta S (2009) Extraction, characterization, stability and biological activity of flavonoids isolated from chamomile flowers. Mol Cell Pharmacol 1(3):138

19. Bhattacharya S, Mondal L, Mukherjee B, Dutta L, Ehsan I, Debnath MC, Gaonkar RH, Pal MM, Majumdar S (2018) Apigenin loaded nanoparticle delayed development of hepatocellular carcinoma in rats. Nanomed Nanotechnol Biol Med 14(6):1905-1917. https://doi.org/10.1016/.nano.2018. 05.011

20. Paini M, Daly SR, Aliakbarian B, Fathi A, Tehrany EA, Perego P, Dehghani F, Valtchev P (2015) An efficient liposome based method for antioxidants encapsulation. Colloids Surf B Biointerfaces 136:1067-1072

21. Banerjee K, Banerjee S, Das S, Mandal M (2015) Probing the potential of apigenin liposomes in enhancing bacterial membrane perturbation and integrity loss. J Colloid Interface Sci 453:48-59. https://doi.org/10.1016/j.jcis.2 015.04.030
22. Shen $L N$, Zhang $Y T$, Wang $Q, X u L$, Feng NP (2014) Enhanced in vitro and in vivo skin deposition of apigenin delivered using ethosomes. Int J Pharm 460(1-2):280-288. https://doi.org/10.1016/j.jpharm.2013.11.017

23. Karim R, Palazzo C, Laloy J, Delvigne AS, Vanslambrouck S, Jerome C, Lepeltier E, Orange F, Dogne JM, Evrard B, Passirani C (2017) Development and evaluation of injectable nanosized drug delivery systems for apigenin. Int J Pharm 532(2):757-768. https://doi.org/10.1016/j.ijpharm.2017.04.064

24. Banerjee K, Banerjee S, Mandal M (2017) Enhanced chemotherapeutic efficacy of apigenin liposomes in colorectal cancer based on flavonemembrane interactions. J Colloid Interface Sci 491:98-110. https://doi.org/1 0.1016/j.jcis.2016.12.025

25. Arsic I, Tadic V, Vlaovic D, Homsek I, Vesic IG, Vuleta G (2011) Preparation of novel apigenin-enriched, liposomal and non-liposomal, antiinflammatory topical formulations as substitutes for corticosteroid therapy. Phytother Res 25(2):228-233

\section{Publisher's Note}

Springer Nature remains neutral with regard to jurisdictional claims in published maps and institutional affiliations.

\section{Submit your manuscript to a SpringerOpen ${ }^{\circ}$ journal and benefit from:}

- Convenient online submission

- Rigorous peer review

- Open access: articles freely available online

- High visibility within the field

- Retaining the copyright to your article

Submit your next manuscript at $\boldsymbol{\nabla}$ springeropen.com 